Portland State University

PDXScholar

\title{
Identifying Factors Associated With Falls in Postmenopausal Breast Cancer Survivors: A Multi- Disciplinary Approach
}

\author{
Kerri M. Winters-Stone \\ Oregon Health \& Science University \\ Britta Torgrimson \\ Oregon Health \& Science University \\ Fay Horak \\ Oregon Health \& Science University \\ Alvin Eisner \\ Portland State University, aeisnerphd@gmail.com \\ Lillian Nail \\ Oregon Health \& Science University \\ Follow this and additional works at: https://pdxscholar.library.pdx.edu/commhealth_fac \\ Part of the Oncology Commons, and the Ophthalmology Commons \\ Seepextragefor additional authors
}

\section{Citation Details}

Winters-Stone, Kerri M.; Torgrimson, Britta; Horak, Fay; Eisner, Alvin; Nail, Lillian; Leo, Micahel C.; Chui, Steve; and Luoh, Shiuh-Wen, "Identifying Factors Associated With Falls in Postmenopausal Breast Cancer Survivors: A Multi-Disciplinary Approach" (2010). Community Health Faculty Publications and Presentations. 60.

https://pdxscholar.library.pdx.edu/commhealth_fac/60

This Post-Print is brought to you for free and open access. It has been accepted for inclusion in Community Health Faculty Publications and Presentations by an authorized administrator of PDXScholar. Please contact us if we can make this document more accessible: pdxscholar@pdx.edu. 


\section{Authors}

Kerri M. Winters-Stone, Britta Torgrimson, Fay Horak, Alvin Eisner, Lillian Nail, Micahel C. Leo, Steve Chui, and Shiuh-Wen Luoh 


\title{
Identifying factors associated with falls in postmenopausal breast cancer survivors: a multi-disciplinary approach
}

\author{
Kerri M. Winters-Stone, PhD, Fay Horak, PhD, PT, Alvin Eisner, PhD, Michael C. Leo, PhD, \\ RN, Steve Chui, MD, and Shiuh-Wen Luoh, MD \\ School of Nursing (Winters-Stone, Torgrimson, Leo, Nail), School of Medicine (Chui, Eisner, \\ Horak, Luoh), Oregon Health \& Science University, Portland, OR,From Portland Veterans Affairs \\ Medical Center, Portland, OR (Luoh)
}

\section{Abstract}

Objective-To identify neuromuscular, balance and vision factors that contribute to falls in recently treated breast cancer survivors (BCS) and explore links between fall risk factors and cancer treatment

Design-Case-control plus prospective observation

Setting-Comprehensive cancer center

Participants-BCS within two years chemotherapy completion and/or on adjuvant endocrine therapy $(\mathrm{N}=59$; mean age: $58 \mathrm{yrs})$

Intervention-not applicable

Main outcome measures-Objective measures of postural control, vision and neuromuscular function included 1) a sensory organization test (SOT), 2) a visual assessment battery, 3) muscle mass by DXA, and 4) neuromuscular function with strength by repetition maximum, power by timed stair climb, and gait speed by $4 \mathrm{~m}$ walk. Falls were self-reported for the past year (retrospective) and monthly for six months (prospective).

Results-58\% of BCS reported falls in the past year. BCS with a history of falls had lower SOT scores with a vestibular deficit pattern in postural control $(\mathrm{p}<.01)$ and took longer to read letters on the contrast sensitivity chart $(\mathrm{p}<.05)$. Vestibular score on the SOT mediated the relationship between treatment and falls among BCS who received chemotherapy only, but not adjuvant endocrine therapy.

Conclusions-Results of this pilot project suggest that balance disturbances of vestibular origin and delays in detecting low contrast visual stimuli are associated with falls in BCS. Future studies that track falls and fall risk factors in BCS from diagnosis through treatment are warranted as are studies that can identify treatment-related vestibular dysfunction and altered visual processing.

\footnotetext{
(C) 2010 The American Congress of Rehabilitation Medicine. Published by Elsevier Inc. All rights reserved.

Author for Correspondence and Reprint Requests: Kerri Winters-Stone, PhD, Associate Professor, Oregon Health \& Science University, 3455 SW US Veteran's Hospital Rd, Mailcode: SN-ORD, Portland, OR 97239, Voice: 503-494-0813, Fax: 503-418-0903, wintersk@ohsu.edu.

Publisher's Disclaimer: This is a PDF file of an unedited manuscript that has been accepted for publication. As a service to our customers we are providing this early version of the manuscript. The manuscript will undergo copyediting, typesetting, and review of the resulting proof before it is published in its final citable form. Please note that during the production process errors may be discovered which could affect the content, and all legal disclaimers that apply to the journal pertain.
} 


\section{Keywords}

drug therapy; neoplasm; postural balance; vision; muscle strength

Fractures are a particular concern for breast cancer survivors $(B C S)^{1,2}$ because of the combined effect of chemotherapy and adjuvant endocrine therapy on fracture risk factors, including bone mass $^{2}$ and fall risk ${ }^{3}$. Even though falls may play an important role in fracture etiology 4 , there are few studies of falls in BCS. We reported that BCS with chemotherapyinduced amenorrhea fall more than their age-matched, cancer-free peers ${ }^{5}$ and Chen et al (2005) reported an increased falls in BCS using data from the Women's Health Initiative cohort $^{3}$.

In older adults, leading risk factors for falls include a prior history of falls, muscle weakness, gait and/or balance impairment and poor vision ${ }^{6-8}$. Cancer treatment may increase fall risk because treatment can worsen traditional risk factors, potentiate less common risk factors or contribute to falls in new ways. Breast cancer chemotherapy may cause peripheral neuropathy ${ }^{9}$ and weakness ${ }^{10}$. Adjuvant endocrine therapy has unknown effects on neuromuscular function and may alter vision in several ways ${ }^{11-15}$. Despite study limitations that included examination of few fall risk factors and use of simple balance and strength assessments, prior work suggests that both balance and strength are worse in estrogendeficient BCS compared to controls and that falls are more common in BCS with muscle weakness 5 .

The purpose of this study was to compare BCS with and without a recent history of falls on a comprehensive battery of objective tests of fall risk factors. The objectives of this study were to: 1) identify balance, neuromuscular and visual factors associated with past history of falls in BCS, 2) determine if factors that discriminate past fallers from non-fallers can predict future falls and 3) examine whether balance, neuromuscular and visual factors are potential mediators of the relationship between the type of cancer treatment and falls.

\section{METHODS}

\section{Sample and Setting}

Women were recruited through state and hospital cancer registries, clinician referral, and community events. To best evaluate persistent treatment effects rather than acute side effects of cancer chemotherapy that might be linked to falls, eligibility criteria included a diagnosis of non-metastatic breast cancer (stages 0-IIIa), completion of chemotherapy within the past two years with or without adjuvant hormone therapy OR within two years of surgery and presently taking a selective estrogen receptor modulator (SERM) or aromatase inhibitor (AI) that was initiated $\geq 6$ months earlier, postmenopausal, and $<70$ years of age (to separate treatment effects from aging). Women were excluded if they had cognitive difficulties or medical conditions that, in the opinion of the study investigator (KWS), affected testing protocols. A convenience sample of $\mathrm{N}=60$ was chosen for this preliminary study, balancing available resources, while retaining power for regression models. The Institutional Review Board approved the study.

\section{Procedures}

Women who responded to invitation letters from the cancer registry, advertisements, or oncologist referral were contacted by telephone and screened for eligibility. Eligible women who agreed to participate provided written informed consent, completed questionnaires and underwent balance, neuromuscular and vision testing. Tests were performed by the same technician except for the SOT that was administered by one of two trained physical 
therapists. All tests followed standard operating procedures that included moderate verbal encouragement. Participants also completed mailed or emailed monthly fall reports for the next six months. Late reports ( $>2$ weeks) were followed up by phone and information obtained verbally.

\section{Measures}

Demographic and clinical characteristics including breast cancer stage, treatment type, diagnosis and treatment dates were obtained by self-report.

Falls were assessed retrospectively through self-report of falls in the previous year and prospectively for six months by monthly reports. A fall was defined as unintentionally coming to rest on the ground or at some other lower level, not as a result of a major intrinsic event or overwhelming hazard ${ }^{16}$. A past fall was only counted if it occurred within the past year and after cancer diagnosis. To reduce reporting bias, we used a standard definition of a fall, gave identical instructions for tracking falls to all participants regardless of fall history, and confirmed affirmative fall reports by telephone.

Balance problems consistent with neuropathy, vestibular loss, and CNS disorders that contribute to fall risk $^{17}$ were assessed by computerized dynamic posturography $(\mathrm{CDP})^{\mathrm{a}}$. We conducted the sensory organization test (SOT) that systematically removes or alters useful visual and somatosensory input across six sensory conditions (Fig 1) and provides equilibrium scores for each condition based on center of gravity sway. Sensory analysis ratios are calculated to identify the degree to which a person can use information from the somatosensory (SOM), visual (VIS) and vestibular (VEST) sensory systems to maintain balance, by comparing conditions 2 to 1,4 to 1 and 5 to 1 , respectively. The preference ratio (PREF) determines reliance on visual information to maintain balance even when the visual information is incorrect from sway-referencing the visual surround (Conditions 3 vs 6 and 2 vs 5).

Gait speed $(\mathrm{m} / \mathrm{s})$ was evaluated by timing the participant as she walked in a straight line for $4 \mathrm{~m}$ at both normal and fast walking speeds on an electronic gait mat ${ }^{\mathrm{b}}$. Slow gait speed is associated with increased fall risk ${ }^{6}$.

Neuromuscular function was evaluated by the following tests: 1) Maximal lower body strength by a one-repetition maximum leg press $(1-\mathrm{RM} ; \mathrm{kg})^{\mathrm{c}}$, using standard protocols $\left.{ }^{18}, 2\right)$ Functional lower body strength by time to rise 5 times from a chair $(\mathrm{sec})^{19}$ and 3) Functional stair climb ability, a task that relies on muscular power, by time to ascend and time to descend seven stairs $(1.2 \mathrm{~m})$ using standard protocols ${ }^{20}$ and described as stair climb speed $(\mathrm{m} / \mathrm{s})$ and power $(\mathrm{kg} \cdot \mathrm{m} / \mathrm{s})$.

Muscle mass of the whole body was measured via DXA ${ }^{\mathrm{d}}$. Participants lay supine on the table and were positioned according to manufacturer guidelines for regional body composition analysis ${ }^{\mathrm{d}}$. Body composition was expressed as $\%$ whole-body lean mass and leg lean mass $(\mathrm{kg})$. In-house coefficients of variation for lean and fat mass in our laboratory are $<2.0 \%{ }^{21}$.

Vision characteristics were assessed with a visual function battery consisting of the following tests: Visual acuity using autorefractione; 2) Spatial contrast sensitivity (both eyes

\footnotetext{
aNeurocom Clinical Research System, NeuroCom International, Inc., 9570 SE Lawnfield Road, Clackamas, OR 97015 USA

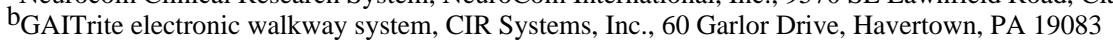

${ }^{c}$ Vectra VX 38 multi-station weight machine, Vectra Fitness, 7901 South 190th Street, Kent, WA 98032 U.S.A

d Hologic Discovery Wi densitometer, Hologic, Inc., 35 Crosby Drive, Bedford, MA 01730

e Humphrey Autorefractor/Keratometer Model 599, Carl Zeiss Meditec Inc., 5160 Hacienda Drive Dublin, CA $94568-7562$
} 
together) using the Pelli-Robson chart at a luminance level of $40 \mathrm{~cd} / \mathrm{m} 2,{ }^{\mathrm{f}} 22$. To assess task difficulty, we recorded "Time to Hesitation" as the time from the start of the test at highest contrast until subject first hesitated $\geq 5$ seconds between successive letters at lower contrasts; 3) Depth perception for near vision was assessed using the Randot@ SO-002 Graded Circle Stereoacuity Test $\mathrm{g}$; 4) Visual field sensitivity was measured using a white-onwhite central $30^{\circ}$ screening test ${ }^{\mathrm{h}}$.

\section{Statistical analysis}

Descriptive data for continuous variables are presented as means and standard deviations and for categorical data as \% of sample. Independent samples t-tests or chi-square were used for comparisons on balance, neuromuscular, vision and treatment characteristics between BCS with and without a history of falls. To explore predictors of falls over and above a history of past falls, hierarchical logistic multiple regression was used to examine treatment, balance, neuromuscular and vision variables that predicted fall status in the 6 month followup period with variables that differed between groups at $\mathrm{p}<.15$ considered for inclusion in the logistic regression model as independent variables. Treatment was dummy coded to examine the independent contributions of chemotherapy and adjuvant endocrine therapy to fall prediction. To examine whether balance, neuromuscular and visual characteristics mediate the relationship between treatment and falls we employed the product coefficients approach to testing mediation $23,24,25$. Only variables significantly different between fallers and non-fallers at baseline were explored as mediators.

\section{RESULTS}

Falls

Of the 143 women who expressed in the study, 59 women enrolled and all completed baseline testing and six-month fall reports. On average, participants were 58 years old and overweight (Table 1). Most women had Stage I-II breast cancer, were treated with chemotherapy and were currently taking a SERM or an AI. At enrollment, 58\% reported a fall in the previous year and half of them experienced $>1$ fall (Table 2). Less than $10 \%$ of the sample had a fracture after their cancer diagnosis, but most reported fractures were associated with a fall. $53 \%$ of our sample experienced one or more falls during the sixmonth follow up period. One-third of women with a previous fall history also fell in the 6month follow up period. Taking both observation periods into account, $76 \%$ of BCS in this study reported falling after their cancer diagnosis within the 18-month time frame.

\section{Differences between past fallers and non-fallers}

Past fallers and non-fallers were of similar age and clinical status regarding breast cancer history (Table $3 \& 4$ ). Past fallers had lower scores on condition 5 of the SOT (p<.01) (Fig 1) which contributed to differences on the VEST score $(\mathrm{p}<.01)$ (Table 4). Subjects who took longer time to read letters on the contrast sensitivity chart were more likely to have a history of falls ( $\mathrm{p}<.05$; Table 5). There were no other significant differences on the SOT, the muscle function tests or the visual tests by fall history.

\section{Predictors of future falls}

After adjusting for fall history, the following variables were added in the regression model: VEST score, VIS score, whole body \% lean mass, stair descent speed, time to hesitation, and

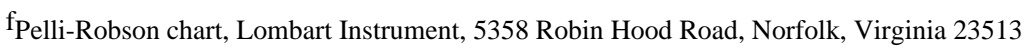

gStereo Optical Co. Inc. 8623 W. Bryn Mawr Ave., Suite 502 Chicago, IL 60631

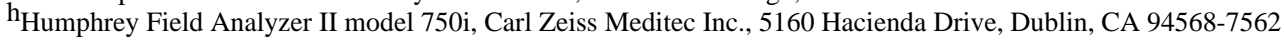


treatment type. Though stair ascent speed met our criterion for entry in the model $(\mathrm{p}<.15)$ it was not included in the regression because of its large correlation with stair descent speed and concern for multicollinearity. Time to (visual) hesitation and stair descent speed introduced instability in the estimates of the standard errors so the model was rerun without these variables. The final logistic regression model was not significant, $\chi^{2}(6)=3.85, p>$. 05; Table 6.

\section{Mediators of the relationship between treatment and falls}

VEST score was the only variable that met criteria for mediator models. Separate models were run to examine whether VEST score mediated the relationship between past or future falls and a particular treatment category (adjuvant endocrine therapy, chemotherapy, or adjuvant endocrine therapy + chemotherapy). Treatment type had an indirect relationship with past falls due to balance problems when relying on the vestibular system (Table 7). The chemotherapy only group was 1.96 times more likely to have a history of falls than the group that received chemotherapy + endocrine therapy via the effect of treatment on VEST score (95\% bias-corrected and accelerated CI for the odds ratio: 1.05-6.38). VEST score did not mediate the relationship between treatment type and future falls.

\section{DISCUSSION}

Our study is the first to consider how breast cancer treatment may increase fall risk by using a comprehensive set of objective measures of fall risk and by exploring mediators of the treatment-falls relationship. Our findings suggest that recently treated postmenopausal BCS have higher rates of falling compared to population averages for community-dwelling older adults and that balance disturbances may explain how treatment could increase falls in BCS. Difficulties responding quickly to low spatial contrasts may also contribute to falls in this population, in which vision disturbances associated with adjuvant endocrine therapy have been reported ${ }^{11-15}$. By aggregating fall history data and prospective fall data, $76 \%$ of BCS fell within an 18-month period. Alterations in vestibular inputs to balance control may explain the relationship between breast cancer treatment and falls observed in women whose systemic treatment was cytotoxic chemotherapy alone.

Among our sample of postmenopausal BCS, the incidence of falls is nearly double the $25 \%$ $30 \%$ annual fall rate reported for community-dwelling older adults over 65 years of age ${ }^{26}$. In our study, $58 \%$ of BCS experienced a fall in the year prior to enrollment and nearly half $(47 \%)$ fell within six-months thereafter. Our results agree with those reported by Chen et al (2005) that BCS have a $15 \%$ higher risk of falls than non-BCS ${ }^{3}$. In contrast, studies in older cancer survivors report similar fall histories between older adults receiving treatment for cancer and cancer-free older adults ${ }^{27,28}$. Age and treatment differences may explain the discrepancies between falls data in BCS studies versus studies of older adults with mixed cancer diagnoses. At least in BCS, higher fall risk should be considered as a potential consequence of treatment. In turn, falls may lead to injury, activity limitations due to fear of falling ${ }^{29}$, and eventually contribute to functional decline $\mathrm{e}^{30}$.

We measured a comprehensive set of neuromuscular and balance characteristics known to be associated with falls but only balance discriminated fallers from non-fallers. BCS who fell had significantly lower scores on condition 5 of the SOT, indicating a vestibular-related deficit in balance control. Using similar methods, Wampler (2007) reported lower scores on five of six SOT tests, and particularly lower vestibular scores among BCS treated with taxane therapy compared to healthy, age-matched controls ${ }^{31}$. SOT scores from our BCS group are similar to those of Wampler's BCS sample, but vestibular scores among the fallers in our study are even lower and sway in other conditions was not abnormal. The similar SOT results for vestibular scores reported for both studies may reflect a consistent side 
effect of breast cancer treatment, particularly chemotherapy. Doxobubicin (adriamycin), used in most combination chemotherapy for breast cancer, is an aminoglycoside. This class of drugs is associated with vestibular ototoxicity ${ }^{32}$. Ototoxic side effects from chemotherapy drugs for breast cancer have received very little attention in the literature. Of the two studies including BCS, aminoglycosides were linked to ototoxicity in BCS only ${ }^{33}$, while ototoxicy from taxanes was not observed in breast plus ovarian cancer survivors ${ }^{7}$. Ototoxicity results in loss of hair cells in the vestibular system even before noticeable hair cell loss in the cochlea for hearing and consistently results in abnormal scores in SOT conditions 5 and 6 , despite normal sway in conditions $1-4^{34}$. Together, our study and Wampler's suggest that breast cancer treatment may adversely affect the vestibular inputs to balance control and this may lead to falls. However, since past, but not future falls could be predicted by balance problems, it is possible that vestibular or other deficits impairing balance function were most severe during and immediately following chemotherapy and lessen over time or are compensated for by increased reliance on other sensory systems to maintain balance ${ }^{35}$.

Wampler et al (2007) also reported that BCS treated with taxane-based chemotherapy had worse visual acuity at low but not high-contrast, as compared with healthy control subjects. In our study the average contrast sensitivity level itself was not significantly different between fallers and non-fallers which could be because the Pelli-Robson test assesses contrast sensitivity far above the visual acuity limit. In addition, we found the relation of falls to contrast sensitivity to depend on the time taken by subjects to respond correctly. In the absence of time constraints, subjects may view the low-contrast letters for upwards of ten seconds before identifying the correct letters. A decision period this long would be of little help to a person navigating real-world environments where falls occur. Our results may help explain discrepancies in the literature on the relation of contrast sensitivity to falls ${ }^{36-38}$.

In the mediator models, chemotherapy treatment had an indirect effect on falls through its effect on vestibular balance scores when contrasted with the group that received chemotherapy + adjuvant endocrine therapy where no relationship with vestibular balance scores and falls existed. However, there was no indirect effect found for adjuvant endocrine therapy only and falls via vestibular scores when compared to those who received chemotherapy + adjuvant endocrine therapy. The differences between treatment groups may be confounded by different health and disease status of the patient that dictated type of treatment. Women who do not receive adjuvant endocrine therapy for breast cancer are more likely to have hormone receptor negative disease that is not responsive to SERMs or AIs ${ }^{39}$. These BCS may be more likely to receive high-dose chemotherapy ${ }^{40}$ and/or anthracyclinebased chemotherapy ${ }^{41}$ thus, may be more vulnerable to side effects of this type of chemotherapy treatment. Given the variation in dose and type of chemotherapy and the impact of these variations on the nature and magnitude of treatment-related side effects, it will be important for future studies to obtain complete treatment information on participants and/or focus on specific chemotherapeutic agents.

\section{Study Limitations}

Our study has limitations. The analyses using retrospective falls data are cross-sectional and cannot establish cause and effect; in fact, we only counted falls that occurred in the past year and after cancer diagnosis to retain the plausible link to cancer treatment. Due to challenges inherent to abstracting medical records from diverse hospital systems among our community sample, we were unable to obtain full information on chemotherapy drugs and doses received by participants so we cannot link specific chemotherapy agents to falls. We did not include measures of peripheral neuropathy, a common side effect of chemotherapy associated with falls; however, the SOT somatosensory scores were similar between fallers and non-fallers (Fig 1) suggesting that peripheral neuropathy may not underlie balance problems in this sample. Our study may have attracted women concerned about falling and 
results may not generalize to the broader population of BCS. Our sample size was relatively small but appropriate for preliminary work and intended to inform future studies.

\section{CONCLUSIONS}

Falls in BCS are understudied and deserve more attention, particularly in light of the increase in fractures after breast cancer treatment and the relationship of falls to fractures. Our findings add to growing evidence that fall risk is increased in BCS and that vestibular function may underpin associations between breast cancer treatment and falls. Our results also suggest that standard contrast sensitivity tests may not capture delays in contrast detection that might contribute to falls. Collectively, knowledge from this study will inform future studies of falls in cancer survivors as well as contribute to the development of specific interventions that target BCS at risk of falling. To date, only strength training has been examined for effects on falls in $\mathrm{BCS}^{42}$. This study did not specifically target BCS who fell and exercise did not reduce falls. Given our findings suggesting that strength is not a predictor of falls in BCS, strength training less effective in BCS than in older adults where strength is a predictor of falls. Future studies may consider a multi-factorial interventions for reducing falls that include vestibular rehabilitation techniques and environmental modifications to enhance contrast.

\section{Acknowledgments}

Funding: This publication was made possible with support from the Oregon Clinical and Translational Research Institute (OCTRI), grant number UL1 RR024140 from the National Center for Research Resources (NCRR), a component of the National Institutes of Health (NIH), and NIH Roadmap for Medical Research.

We certify that no party having a direct interest in the results of the research supporting this article has or will confer a benefit on us or on any organization with which we are associated AND, if applicable, we certify that all financial and material support for this research (eg, NIH or NHS grants) and work are clearly identified in the title page of the manuscript.

\section{List of abbreviations}

$\begin{array}{ll}\text { BCS } & \text { breast cancer survivor } \\ \text { SOT } & \text { sensory organization test } \\ \text { CNS } & \text { central nervous system } \\ \text { CDP } & \text { computerized dynamic posturography } \\ \text { SOM } & \text { somatosensory } \\ \text { VEST } & \text { vestibular } \\ \text { VIS } & \text { vision } \\ \text { PREF } & \text { preference } \\ \text { 1-RM } & \text { one-repetition maximum } \\ \text { m/s } & \text { meters per second } \\ \text { kg·m/s } & \text { kilogram-meters per second } \\ \text { DXA } & \text { dual energy x-ray absorptiometry } \\ \text { cd } / \mathbf{m}^{2} & \text { candela per square meter } \\ \text { SERM } & \text { selective estrogen receptor modulator } \\ \text { AI } & \text { aromatase inhibitor }\end{array}$


SE standard error

confidence interval

\section{References}

1. Kanis JA, McCloskey EV, Powles T, Paterson AH, Ashley S, Spector T. A high incidence of vertebral fracture in women with breast cancer. Br J Cancer. 1999; 79:1179-81. [PubMed: 10098755]

2. ATAC Trialists' Group. Results of the ATAC (Arimidex, Tamoxifen, Alone or in Combination) trial after completion of 5 years' adjuvant treatment for breast cancer. The Lancet. 2005; 365:60-2.

3. Chen Z, Maricic M, Bassford TL, Pettinger M, Ritenbaugh C, Lopez AM, Barad DH, Gass M, Leboff MS. Fracture risk among breast cancer survivors: results from the Women's Health Initiative Observational Study. Arch Int Med. 2005; 165:552-8. [PubMed: 15767532]

4. Frost HM. Should fracture risk-of-fracture analyses include another major risk factor? The case for falls. J Clin Densitom. 2001; 4:381-3. [PubMed: 11748343]

5. Winters-Stone KM, Nail L, Bennett JA, Schwartz A. Bone health and falls: Fracture risk in breast cancer survivors with chemotherapy-induced amenorrhea. Oncol Nurs Forum. 2009; 36:315-25. [PubMed: 19596649]

6. American Geriatrics Society, British Geriatrics Society and American Academy of Orthopaedic Surgeons Panel on Falls Prevention. Guideline for the prevention of falls in older persons. J Am Geriatr Soc. 2001; 49:664-72. [PubMed: 11380764]

7. Sarafraz M, Ahmadi K. Paraclinical evaluation of side-effects of Taxanes on auditory system. Acta Otorhinolaryngol Ital. 2008; 28:239-42. [PubMed: 19186452]

8. Dhital A, Pey T, Stanford MR. Visual loss and falls: a review. Eye. 2010; 24:1437-46. [PubMed: 20448666]

9. Kuroi K, Shimozuma K. Neurotoxicity of taxanes: symptoms and quality of life assessment. Breast Cancer. 2004; 11:92-9. [PubMed: 14718800]

10. Mold JW, Vesely SK, Keyl BA, Schenk JB, Roberts M. The prevalence, predictors, and consequences of peripheral sensory neuropathy in older patients. J Am Board Fam Pract. 2004; 17:309-18. [PubMed: 15355943]

11. Eisner A, Austin DF, Samples JR. Short wavelength automated perimetry and tamoxifen use. Br J Ophthalmol. 2004; 88:125-30. [PubMed: 14693789]

12. Epstein RJ. Visual impairment in myopic patients with breast cancer receiving adjuvant therapy with aromatase inhibitors. Clin Breast Cancer. 2009; 9:184-6. [PubMed: 19661043]

13. Eisner A, Incognito LJ. The color appearance of stimuli detected via short-wavelength-sensitive cones for breast cancer survivors using tamoxifen. Vision Res. 2006; 46:1816-22. [PubMed: 16364390]

14. Eisner A, Toomey MD, Falardeau J, Samples JR, Vetto JT. Differential effects of tamoxifen and anastrozole on optic cup size in breast cancer survivors. Breast Cancer Res Treat. 2007; 106:16170. [PubMed: 17260092]

15. Coombes RC, Hall E, Gibson LJ, et al. A randomized trial of exemestane after two to three years of tamoxifen therapy in postmenopausal women with primary breast cancer. New Engl J Med. 2004; 350:1081-92. [PubMed: 15014181]

16. Tinetti M, Williams C. Falls, injuries due to falls, and the risk of admission to a nursing home. N Engl J Med. 1997; 337:1279-84. [PubMed: 9345078]

17. Whitney SL, Marchetti GF, Schade AI. The relationship between falls history and computerized dynamic posturography in persons with balance and vestibular disorders. Arch Phys Med Rehab. 2006; 87:402.

18. American College of Sports Medicine. ACSM's guildelines for exercise testing and prescription. 7. Philadelphia: Lippincott Williams \& Wilkins; 2006.

19. Guralnik J, Simonsick E, Ferrucci L, Glynn RJ, Berkman LF, Blazer DG, Scherr PA, Wallace RB. A short physical performance battery assessing lower extremity function: association with self- 
reported disability and prediction of mortality and nursing home admission. J Gerontol. 1994; 49:M85-94. [PubMed: 8126356]

20. Bean JF, Kiely DK, LaRose S, Alian J, Frontera WR. Is stair climb power a clinically relevant measure of leg power impairments in at-risk older adults? Arch Phys Med Rehab. 2007; 88:604.

21. Winters KM, Snow CM. Detraining reverses positive effects of exercise on the musculoskeletal system in premenopausal women. J Bone Miner Res. 2000; 15:2495-503. [PubMed: 11127215]

22. Rubin GS, West SK, Munoz B, Bandeen-Roche K, Zeger S, Schein O, Fried LP. A comprehensive assessment of visual impairment in a population of older Americans. The SEE Study. Salisbury Eye Evaluation Project. Invest Ophthalmol Vis Sci. 1997; 38:557-68. [PubMed: 9071208]

23. Hayes AF. Beyond Baron and Kenny: Statistical mediation analysis in the new millennium. Communication Monographs. 2009; 76:13p.

24. MacKinnon DP, Lockwood CM, Williams J. Confidence limits for the indirect effect. Multivariate Behavioral Research. 2004; 39:30p.

25. MacKinnon DP, Lockwood CM, Hoffman JM, West SG, Sheets V. A comparison of methods to test mediation and other intervening variable effects. Psych Methods. 2002; 7:83-104.

26. Hornbrook M, Stevens V, Wingfield D, Hollis J, Greenlick M, Ory M. Preventing falls among community-dwelling older persons: results from a randomized trial. Gerontologist. 1994; 34:1623. [PubMed: 8150304]

27. Overcash JA, Beckstead J. Predicting falls in older patients using components of a comprehensive geriatric assessment. Clin J Oncol Nurs. 2008; 12:941-9. [PubMed: 19064388]

28. Overcash J. Prediction of falls in older adults with cancer: a preliminary study. Oncol Nurs Forum. 2007; 34:341-6. [PubMed: 17573298]

29. Salkeld G, Cameron I, Cumming R, Easter S, Seymour J, Kurrle SE, Quine S. Quality of life related to fear of falling and hip fracture in older women: a time trade off study. BMJ. 2000; 320:341-6. [PubMed: 10657327]

30. Deshpande N, Metter EJ, Lauretani F, Bandinelli S, Guralnik J, Ferrucci L. Activity restriction induced by fear of falling and objective and subjective measures of physical function: a prospective cohort study. J Am Geriatr Soc. 2008; 56:615-20. [PubMed: 18312314]

31. Wampler MA, Topp KS, Miaskowski C, Byl NN, Rugo HS, Hamel K. Quantitative and clinical description of postural instability in women with breast cancer treated with taxane chemotherapy. Arch Phys Med Rehab. 2007; 88:1002-8.

32. Black FO, Pesznecker SC. Vestibular ototoxicity. Clinical considerations. Otolaryngol Clin North Am. 1993; 26:713-36. [PubMed: 8233485]

33. Jenkins V, Beveridge H, Low R, Mitra S. Atypical hearing loss in women with breast cancer receiving adjuvant treatment. Breast. 2006; 15:448-51. [PubMed: 16135407]

34. Black FO. What can posturography tell us about vestibular function? Ann N Y Acad Sci. 2001; 942:446-64. [PubMed: 11710483]

35. Horak FB. Postural compensation for vestibular loss and implications for rehabilitation. Restor Neurol Neurosci. 2010; 28:57-68. [PubMed: 20086283]

36. de Boer MR, Pluijm SM, Lips P, et al. Different aspects of visual Impairment as risk factors for falls and fractures in older men and women. J Bone Min Res. 2004; 19:1539-47.

37. Lord SR. Visual risk factors for falls in older people. Age Ageing. 2006; 35(Suppl 2):ii42-ii5. [PubMed: 16926203]

38. Freeman EE, Munoz B, Rubin G, West SK. Visual field loss increases the risk of falls in older adults: the Salisbury eye evaluation. Invest Ophthalmol Vis Sci. 2007; 48:4445-50. [PubMed: 17898264]

39. Chen JQ, Russo J. ERalpha-negative and triple negative breast cancer: molecular features and potential therapeutic approaches. Biochim Biophys Acta. 2009; 1796:162-75. [PubMed: 19527773]

40. Nieto Y, Shpall EJ. High-dose chemotherapy for high-risk primary and metastatic breast cancer: is another look warranted? Current Opinion in Oncology. 2009; 21:150-7. [PubMed: 19532017]

41. Berry DA, Cirrincione C, Henderson IC, Citron ML, Budman DR, Goldstein LJ, Martino S, Perez EA, Muss HB, Norton L, Hudis C, Winer EP. Estrogen-receptor status and outcomes of modern 
chemotherapy for patients with node-positive breast cancer. JAMA. 2006; 295:1658-67.

[PubMed: 16609087]

42. Twiss JJ, Waltman NL, Berg K, Ott CD, Gross GJ, Lindsey AM. An exercise intervention for breast cancer survivors with bone loss. J Nurs Scholarsh. 2009; 41:20-7. [PubMed: 19335674] 


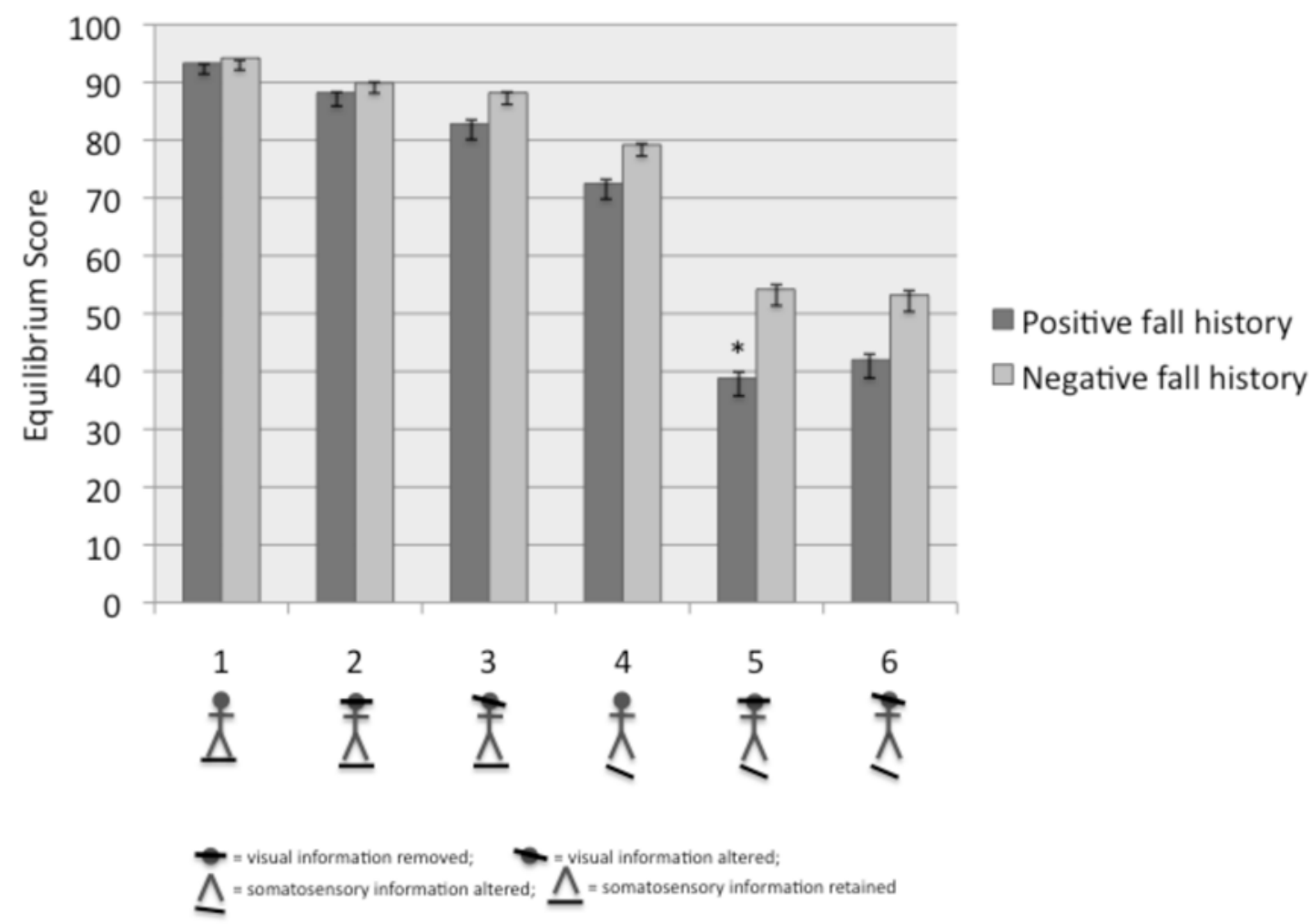

Fig. 1.

Comparison of equilibrium scores by condition on the baseline Sensory Organization Test between BCS with a positive or negative fall history. Figure illustrating the sensory system alterations are placed below each condition number. 
Table 1

Health history of breast cancer survivors $(\mathrm{N}=59)$

\begin{tabular}{lc} 
Treatment & Mean (SD) or \% of Sample \\
\hline Age & $58.5(9.7)$ \\
BMI $\left(\mathrm{kg} / \mathrm{m}^{2}\right)$ & $28.3(7.2)$ \\
Months since diagnosis & $20.9(6.5)$ \\
Stage 0 & $5 \%$ \\
Stage I & $29 \%$ \\
Stage II & $39 \%$ \\
Stage III & $19 \%$ \\
Chemotherapy only (N=17) & $29 \%$ \\
Current adjuvant endocrine therapy (N=19) & \\
$\quad$ SERM use only (N=7) & $12 \%$ \\
$\quad$ Current AI use only (N=12) & $20 \%$ \\
Chemotherapy + current SERM or AI use (N=23) & $39 \%$ \\
\hline
\end{tabular}

Abbreviations: SERM: Selective estrogen receptor modulator; AI: Aromatase inhibitor 


\section{Table 2}

Proportion of falls and fractures reported by breast cancer survivors $(\mathrm{N}=59)$ in the past year* and over the 6month observation period

\begin{tabular}{lc} 
& \% of Sample \\
\hline At least one fall in past year & $58 \%$ \\
Multiple falls in past year & $31 \%$ \\
Recent fracture & $8 \%$ \\
Recent fracture related to fall & $5 \%$ \\
At least one fall occurring over 6 month observation period & $53 \%$ \\
Multiple falls occurring over 6 month observation period & $14 \%$ \\
At least one fall in past year or over 6 month observation period & $76 \%$ \\
\hline
\end{tabular}

fall or fracture must have occurred within the year prior to enrollment and after cancer diagnosis. 


\section{Table 3}

Comparison of participants with positive and negative fall history ${ }^{*}$ on demographic and clinical information (mean (SD) or \% of group) collected at enrollment. Percentages reflect the proportion of the sample possessing a clinical characteristic within each fall group.

\begin{tabular}{lccc} 
& Positive fall history $(\mathbf{N}=\mathbf{3 4})$ & Negative fall history $(\mathbf{N}=\mathbf{2 5})$ & p-value \\
\hline Age (yrs) & $59.2(7.1)$ & $57.4(12.4)$ & 0.52 \\
Time since diagnosis (mos.) & $22.3(5.8)$ & $19.0(7.1)$ & 0.41 \\
Breast cancer stage & & & 0.19 \\
$\quad$ Stage 0 & $9 \%$ & $0 \%$ & -- \\
$\quad$ Stage I & $27 \%$ & $37 \%$ & -- \\
$\quad$ Stage II & $49 \%$ & $32 \%$ & -- \\
$\quad$ Stage III & $15 \%$ & $31 \%$ & -- \\
Treatment & & & \\
Chemotherapy only & $29 \%$ & $28 \%$ & 0.46 \\
Current SERM use only & $15 \%$ & $4 \%$ & 0.28 \\
Current AI use only & $15 \%$ & $24 \%$ & 0.16 \\
Chemotherapy + SERM or AI use & $41 \%$ & $44 \%$ & 0.72 \\
\hline
\end{tabular}

* Number of falls reported over 12 months prior to baseline testing

Abbreviations: $\mathrm{SERM}=$ selective estrogen receptor modulator; $\mathrm{AI}=$ aromatase inhibitor 


\section{Table 4}

Comparison of participants with positive and negative fall history * on baseline neuromuscular and balance characteristics (mean (SD) or \% of group)

\begin{tabular}{lccc} 
& Positive fall history $(\mathbf{n = 3 4})$ & Negative fall history $(\mathbf{N}=\mathbf{2 5})$ & p-value \\
\hline BMI $\left(\mathrm{kg} / \mathrm{m}^{2}\right)$ & $29.3(8.3)$ & $26.9(5.1)$ & 0.22 \\
Whole body \% lean mass & $60.7(6.8)$ & $63.4(6.2)$ & 0.12 \\
Leg lean mass $(\mathrm{kg})$ & $15.0(3.3)$ & $14.4(2.4)$ & 0.46 \\
Maximal leg press $(\mathrm{kg})$ & $86.0(30.4)$ & $78.6(19.5)$ & 0.30 \\
Chair stand time $(\mathrm{sec}$ to complete 5 stands) & $12.6(3.0)$ & $11.8(3.3)$ & 0.31 \\
Stair climb power $(\mathrm{kg} \cdot \mathrm{m} / \mathrm{sec})$ & $28.3(6.7)$ & $28.2(7.0)$ & 0.96 \\
Stair ascent speed $(\mathrm{m} / \mathrm{sec})$ & $.25(.04)$ & $.27(.05)$ & 0.09 \\
Stair descent speed $(\mathrm{m} / \mathrm{sec})$ & $.28(.07) *$ & $.31(.05)$ & 0.07 \\
Best fast walk $(\mathrm{m} / \mathrm{sec})$ & $.43(.07)$ & $.48(.07)$ & 0.21 \\
Average usual walk $(\mathrm{m} / \mathrm{sec})$ & $.30(.05)$ & $.33(.05)$ & 0.21 \\
SOT-somatosensory & $94.6(7.2)$ & $95.6(3.5)$ & 0.52 \\
SOT-visual & $77.6(19.1)$ & $84.1(8.5)$ & 0.12 \\
SOT-vestibular & $41.4(25.0)$ & $57.3(18.7)$ & 0.01 \\
SOT-preference & $96.6(23.6)$ & $98.6(11.5)$ & 0.70 \\
\hline
\end{tabular}

* Number of falls reported over 12 months prior to baseline testing

Abbreviations: SOT: Sensory organization test 
Table 5

Comparison of participants with positive and negative fall history ${ }^{*}$ on baseline vision characteristics (mean (SD) or \% of group)

\begin{tabular}{|c|c|c|c|}
\hline & Positive fall history $(\mathrm{N}=\mathbf{3 4}$ ) & Negative fall history $(\mathrm{N}=25)$ & p-value \\
\hline Visual acuity - right eye ${ }^{\dagger}$ & $0.9(0.2)$ & $0.9(0.3)$ & 0.63 \\
\hline Visual acuity - left eye ${ }^{\dagger}$ & $0.6(0.7)$ & $0.6(0.5)$ & 0.89 \\
\hline Contrast sensitivity ${ }^{t}$ & $1.8(0.2)$ & $1.8(0.2)$ & 0.73 \\
\hline Contrast sensitivity time to hesitation (sec) $)^{\xi}$ & $29.0(10.5)$ & $24.6(6.1)$ & 0.04 \\
\hline Contrast sensitivity at hesitation $\xi$ & $1.7(0.1)$ & $1.7(0.1)$ & 0.99 \\
\hline Stereovision $(\operatorname{arcsec}) / /$ & $88.5(169.0)$ & $173(314.7)$ & 0.63 \\
\hline Visual field sensitivity (\# of missed points) ${ }^{\mathscr{T}}$ & $0.8(2.6)$ & $3.8(8.5)$ & 0.10 \\
\hline
\end{tabular}

* Number of falls reported over 12 months prior to baseline testing;

${ }^{\dagger}$ Scores $<1$ indicate poorer than 20/20 acuity;

thigher scores indicate better contrast sensitivity;

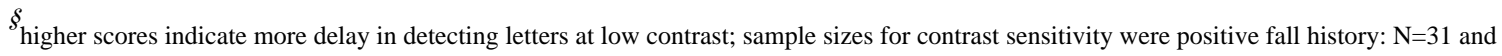
negative fall history: $\mathrm{N}=23$ and for contrast sensitivity hesitation time and line were $\mathrm{N}=29$ and $\mathrm{N}=22$ due to missing data;

/lower scores (arcsec) indicate better stereovision;

Ithigher scores imply poorer coverage of the visual field 


\section{Table 6}

Logistic regression results for prediction of faller status over six-month observation period (odds ratio $+95 \%$ confidence interval). Independent variables were assessed at baseline.

\begin{tabular}{lcc} 
Independent Variable & Odds Ratio & p-value \\
\hline History of falls in previous year & $0.86(0.27,2.69)$ & 0.79 \\
Whole body percent lean mass & $1.00(0.92,1.01)$ & 0.94 \\
SOT-vision & $0.97(0.93,1.01)$ & 0.17 \\
SOT-vestibular & $0.99(0.97,1.03)$ & 0.77 \\
Adjuvant endocrine therapy only ${ }^{*}$ & $1.42(0.41,4.90)$ & 0.58 \\
Chemotherapy only $^{\dagger}$ & $1.32(0.31,5.64)$ & 0.71 \\
\hline
\end{tabular}

* Comparison of participants who only had adjuvant endocrine therapy to participants who had chemotherapy + adjuvant endocrine therapy;

${ }^{\dagger}$ Comparison of participants who had chemotherapy only compared to participants who had chemotherapy + adjuvant endocrine therapy 


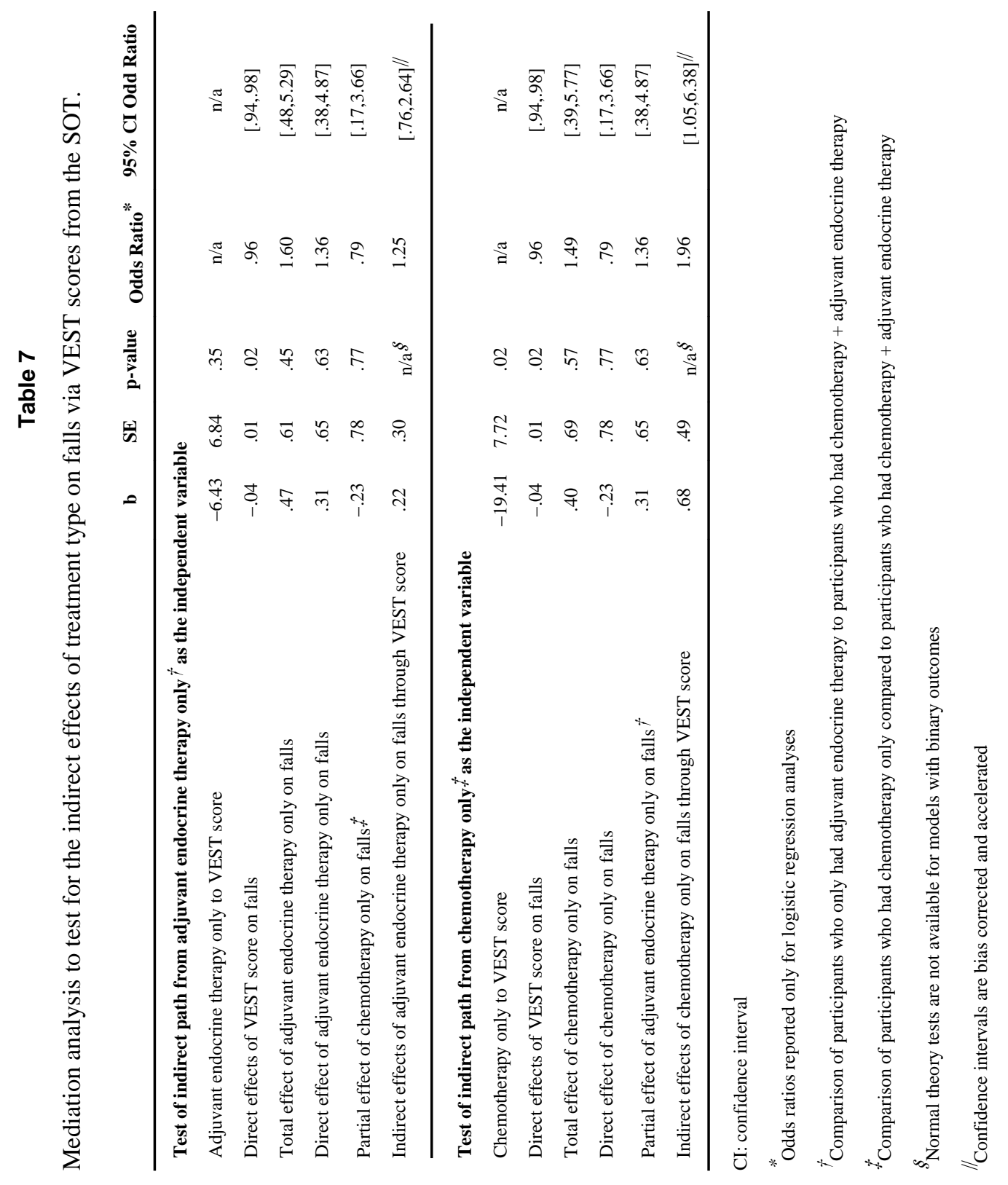

